\title{
De hallazgos y lecturas: Vilma Arêas
}

Mauricio Tenorio

Gabriel Zaid ${ }^{1}$ sostiene una teoría, si sombría, convincente sobre la inútil necesidad de los libros. Tanto libro sirve no más que para dar lugar al esporádico hallazgo, al encuentro fortuito e indescriptible de un lector con su libro. Hallar (poemas, libros, párrafos) es a leer lo que la isla al náufrago. Hay quien oculta el hallar por no revelar ignorancia (¿no conoces a este autor?). Yo hablo desvergonzadamente de lo que hallo.

Mas antes de sumir al lector en mis hallazgos, pongo en claro que no soy quién para hablar de esto. "Some neither can for Wits nor Poets pass", escribió Alexander Pope (1711), "As heavy mules are neither Horse or Ass". Eso: ni poeta ni crítico, pero sí lector. Por ello, deje aquí la lectura el poeta erudito, no prosiga más el crítico profesional, que las de este historiador no son ni más ni menos que impresiones de un vicioso lector de poesía. Mi ignorancia se compensa por mi imparcialidad en el asunto: yo soy de los del lado de la demanda (lectores de poesía), no trabajo del lado de la oferta (poetas, críticos).

Por azares de amigos, viajes y librerías, hace tiempo dos lecturas se cruzaron en mi camino: Men in the Off Hour ${ }^{2}$ de la canadiense Anne Carson y Trouxa Frouxa de la brasileña Vilma Arêas. Dos autoras que nada tenían entre sí a no ser el azar de mi hallazgo y lectura. Hoy sé que Anne Carson es una premiada poetiza en lengua inglesa, pero entonces la hallé gracias a uno de esos favores que uno queda debiendo, en este caso a Fernando Escalante, a quien ya ni espero pagarle tantas caridades. Escalante me había recomendado la novela en verso de la misma autora Autobiography in Red, ${ }^{4}$ la cual me dejó una gratísima impresión y, por supuesto, quedé obligado a seguirle la pista a esta autora experta en literatura clásica griega y latina y que posee una prosa y un verso de envidiable precisión y economía (ambas virtudes escasas en el neo-barroquismo castellano de nuestros días). Vilma Arêas fue otro hallazgo, producto de mis viajes periódicos a Río de Janeiro para caminar de Copacabana a Leblon, tomar café, comprar libros, y conversar hasta cansarse con amigos entrañables. En una librería de Leblon, la dependiente me recomendó el libro de Arêas, y el milagro se cumplió. El libro había encontrado su fortuitito y feliz lector entre Austin, Ciudad de México y Río. De Arêas, yo que no soy ni poeta ni experto en letras brasileñas, no sabía más que lo que decía la solapa del libro: profesora universitaria (como Carson), nacida en Campos y autora de libros de crítica literaria y cuentos, conocedora de dos autoras que me han acompañado por varios años, Clarice Lispector y Sophia de Mello Breyner Andersen.

Escribí poco después una corta nota sobre la lectura paralela de estos dos libros. La publiqué en la sección cultural de un diario mexicano, sólo por compartir hallazgos. Esperaba, en secreto, interesar a lectores más profesionales que yo para que emprendieran la traducción al castellano de mis hallazgos. Mucho después de publicada mi nota supe que eran legión los que compartían mi gusto por ambas autoras. Lección de hallador de libros: en la decepción estamos de común solos, en la fascinación acompañados. En fin, en bibliotecas estadounidenses, encontré dos libros de creación de Arêas: Partidas y $A$ 
terceira perna. ${ }^{5}$ (De su obra crítica no puedo hablar). Descubrí que la lúcida parquedad que me había fascinado en Trouxa Frouxa no era ni un estilo lentamente amasado, ni una incontinencia de la ocurrencia. De lo primero, del estilo, ya en Partidas Arêas lo había explicado en el diálogo entre el oficio de desesperanza y precisión y el de arquitecto de aforismos:

ELA - mas as estórias, se se contam, são todas variações de uma casa tomada: a rota que vai da repartição dos pães (tomemos o amor como metáfora) à evidência do milagre (o desterro). AQUILO QUE SE ESCREVE COM ESTILO É APENAS A FALTA DE CLAREZA PARA ESCREVER SEM ELE.

(Duarte Cabral de Mello)

De lo segundo, de la incontinencia de la ocurrencia, no tiene nada la obra de Arêas. Parece que sólo escribe cuando ha acumulado suficientes fragmentos de existencia que puedan ser expresados como acertijos a caballo entre humor, experimentación narrativa, profundidad conceptual y simples ganas de contar un cuento. Claro, hoy que está de moda en la novela "lo fragmentario" y demás post-cosas, Arêas parece pionera. Pero sus fragmentos no son los de, por ejemplo, un escritor catalán que en un hallazgo me sorprendió, Rafael Argullol ${ }^{6}$, y que luego por seguirlo me apabulló con largas colecciones de ocurrencias al alimón de poemarios y sesudos tratados filosóficos, algunos de ellos dedicados a hablar largamente sobre la imperiosa necesidad de. . callar. No, Arêas calla por costumbre, atesora. Guarda instantes, hasta que salen, listos, pocos, pero indispensables. Lo suyo no era moda en Partidas - un libro que me recordó al recién reeditado Léxico de afinidades ${ }^{7}$ de Ida Vitale, ni fue post-nada en Trouxa Frouxa. Porque son lo mismo: oficio de explorar los límites de lo decible, por ello fragmentos de esencia. Captura de lo que Vitale llama vida:

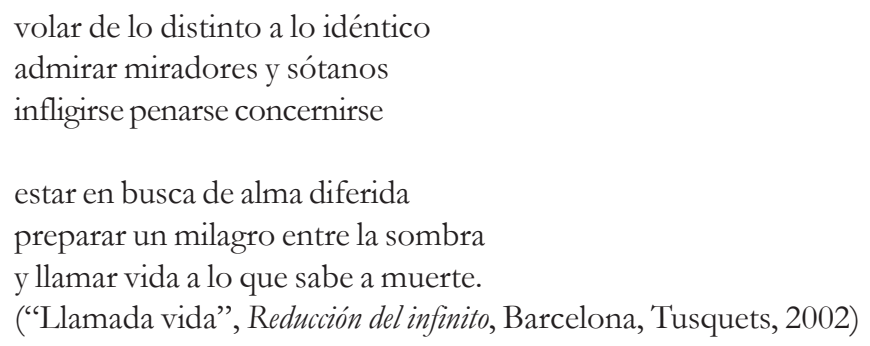

Atrapar de esencias cotidianas pero inolvidables, y Arêas hace esto, eso que a Sophia de Mello Breyner Andersen le cuesta cuatro líneas

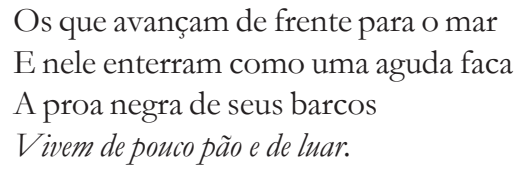

Pero al reescribir estas notas para honrar a Vilma Arêas, no quiero dejar de lado a Carson que fue nativa de mi primer encuentro con la obra de Arêas. Si Carson y Arêas forman un paralelismo impropio, largo otro más inaudito: María Zambrano y Laura Riding. 
La fascinación de mi hallazgo paralelo de Carson y Arêas resultó de la sensación de haber hallado el conocimiento de lo que no existe hasta que vive en la poesía, esa verdad tan real como la muerte, el amor o la vida, pero que no podemos articular hasta que la poesía nombra. Esas cuatro mujeres, Zambrano, Riding, de un lado, y Carson y Arêas, del otro, son los laboratorios y los científicas de este conocimiento. La poesía sufre el martirio del conocimiento, decía Zambrano ${ }^{8}$ " "padece por la lucidez, por la videncia. Padece, porque la poesía sigue siendo mediación y en ella la conciencia no es signo de poder, sino necesidad ineludible para que una palabra se cumpla. Claridad precisa para que lo que está diseñado no más en la niebla, se fije y precise; adquiera "número, peso y medida"'. Zambrano, como Paul Valéry, Eliseo Vivas, Haroldo de Campos o José Ángel Valente, podía teorizar sobre este conocimiento. Yo sólo puedo vivirlo, aprenderlo. Pero el poeta, como Riding, puede ora hablar de la arquitectura de este conocimiento, ora ejercerlo. La poesía, escribió Riding, has been the divine solvent converting knowledge into truth, until knowledge mad with its own modernity, declared itself the sole source of truth (Poetic reality and Critical Unreality, 1928). El poeta puede claudicar a alcanzar esa verdad, como Riding hizo por más de cuarenta años, pero una vez re-conocida en la poesía esa verdad ambigua y profunda, al lector le es imposible des-conocerla:

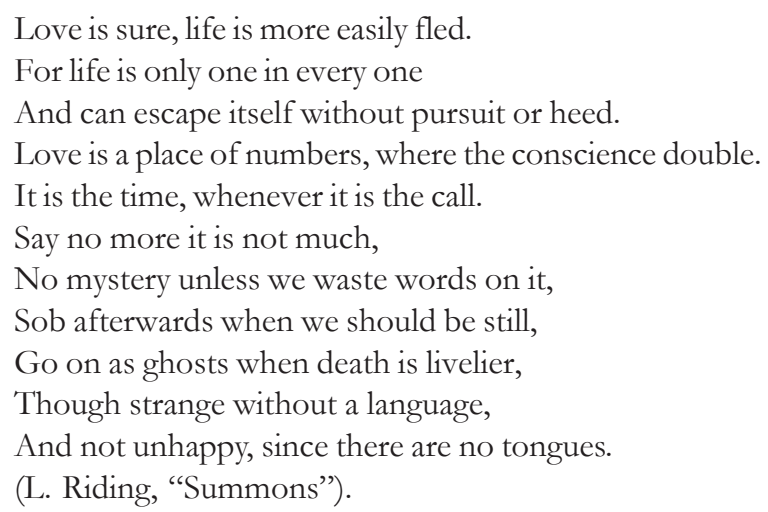

Es el amor la excusa, de Riding, de Arêas, para caminar con palabras sobre el filo de lo indecible, siempre al borde de acabar rasgadas por el acero cortante de lo no conjeturable cuyo efecto desgarrar el lenguaje en palabras sueltas, derramadas y dispersas, entre el silencio. En Arêas, una historia de cárcel y amor (Partidas) remata en la frase aprendida en la prisión, frase de la crueldad que el amor exige y de la simplicidad que el amor no soporta:

VEJO A JANELA, POR EXEMPLO,

VEJO A POREIRA

MAS HÁ MUITAS COISAS QUE NÃO VEJO:

EU NÃO VEJO QUE TE AMO

Mas a frase é muito longa para ser repetida muitas vezes, de sintaxe muito difícil e não ver significa não salvar -se.

Es disecando al amor que Arêas muestra su oficio de profundidad y su vicio de desesperanza y clarividencia ( $A$ terceira perna): 
Mas o paradoxo da forma pura é que ela não tem o direito de estabelecer o que estabelece. Em outras palavras: os amantes são atraídos pelos becos sem saida como os insetos tontos pela lur.

O en esta escena (A terceira perna):

Levando a mão ao rosto (por causa da claridade excessiva exigida pela busca do caminho de volta) sobressalta-se a amante de não encontrar os olhos, o nariz, a boca que brotara (com folhas, flores e fruto) na noite anterior, regada pela saliva do amante.

O problema que se coloca, diz ela, é, sem negar a dureza do prazer como expressão de pura quimera, a reinvenção do rosto.

Pero volviendo a los dos libros que iniciaron mi hallazgo, ellos aún me son difíciles de caracterizar. No son novelas, es más, me parece que quieren ser una querella contra la novela como necesario artificio palabrístico encaminado muchas veces al simple darle cuerpo y espina a un libro. Ambos libros forman, en conjunto, tramas discernibles y claras, pero no siguen una narración convencional. Son trozos, cartas, poemas, pedazos como si fueran los andamios de dos grandes novelas pero que encuentran su felicidad en hacer del arte de sugerir y dejar en esencia todo lo que pudiera ser ampliado y parafraseado de mil maneras. Así Arêas en Partidas o en A terceira perna o en Trouxa Frouxa, o Carson en Autobiography of Red, o en The Beauty of the Husband: a Fictional Essay in 29 Tangos.

Men in the Off Hour inicia con un andante tranquilo que reflexiona sobre "el tiempo ordinario" a través de la visión de la guerra en Viginia Woolf y Tucides. De Woolf se trata de "The Mark in the Wall", ensayo escrito a principios de la Primera Guerra Mundial. Carson habita la manera en que Woolf marcó el inicio no sólo del tiempo de guerra sino del tiempo de escribir sobre la guerra. Pocas páginas las de Carson, pero dejan una sensación ordinaria y sublime de la idea del tiempo de narrar hechos que son por demás humanos y terribles. Tucides y Woolf, a siglos de distancia, unidos por el ojo de Carson, reflexionan sobre ese arranque de la guerra, el cual aunque no creamos predecible, es exacto en cotidianidad y apocalipsis.

Carson continúa con epitafios a la manera clásica, que son para el lector como estaciones poéticas de lucidez filosófica; tramas sobre el conocimiento, el lenguaje y la angustia y paz de escribir. El primero de ellos es memorable, y es para Zion:

\footnotetext{
Murderous little world once our objects had gazes. Our lives Were fragile, the wind

Could dash them away. Here lies the refugee breather Who drank a bowl of elsewhere
}

Trouxa Frouxa, comienza por el título. Trouxa, según el diccionario Aurélio de portugués, del español antiguo troja, carga que se lleva acuestas, pero que en moderno portugués (brasileño) es término a caballo entre paquete, bola de ropa. La unión con el adjetivo Frouxa (flojo, suelto, mal apretado o, también, cobarde), logra un sin número de referencias. Título que es todo un relato. El libro en sí comienza con un corto texto: "Furo na mácula" (una vez más, titulo hallazgo). Un sólo párrafo que va del descubrimiento 
de la "linha circular alongando-se em espinhos ao redor da esfera fuliginosa": una mancha de tinta en el cuaderno de la infancia, al agujero de recuerdos cuya entrada es la mancha. Vistas a través del agujero de la mancha, las cosas parecen nítidas. Los rostros ressurgem inocentes na refração da lágrima, "o que não se vê conduz à sensação correta do que existe. Y de esta historia el libro pasa a distintas narraciones, a veces anecdóticas, otras inconcretas. Incluye, como Men in the Off Hour, diálogos, poemas, líneas sueltas de humor variopinto - de "MÃE/ é como o boil até os chifres se aproveitam", hasta "EXPERIÊNCIA INCOMUNICÁVEL: o minuto preciso em que a dor / rói / (como um rato)/ o resistente vidro da lágrima". Ambas autoras, aquí y allá, reflexionan sobre el dolor del abandono y el amor a través de este resistente vidro. Habla Carson de una ardilla que cuenta con un imperio de ramas y que teme lo mismo que Carson:

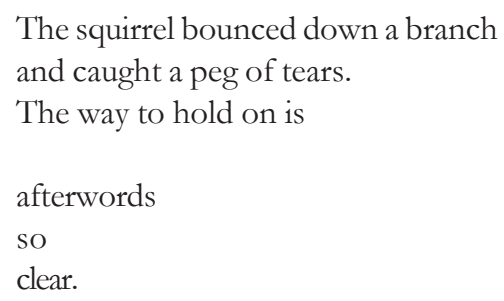

Mas sin duda uno de los más atrayentes momentos de Men in the Off Hour es "Essay on what I think about most". Un delicado texto, escrito en verso, que diserta acerca de lo que, cuando honestos, tememos más: el error, el fallo. Mejor aún, es sobre la utilidad e indispensabilidad del error en el lenguaje. Errar es crear, inadvertidamente, pero crear. Una reflexión que inicia con la metáfora: “¿En que consiste la frescura de la metáfora?" "Aristóteles dice que la metáfora causa a la mente la experiencia de sí misma". Y se alarga en el cuidadoso y erudito examen de los usos del error en la literatura, para caer en versos verdaderos por elocuentes y al revés:

Imitation (mimesis in Greek)

Is Aristotle's collective term for the true mistakes of poetry

What I like about this term

Is the ease with which it accepts

That what we are engaged in when we do poetry is error,

The willful creations of error,

The deliberate break and complication of mistakes

Out of which may arise

Unexpectedness. 
Este ensayo constituye una res poética plena de argumentos filosóficos y filológicos, sin embargo en un lenguaje directo y no por ello falto de sobrecogimientos. Con igual soltura el libro va a caer de verso en verso, de epitafio en epitafio y de una a otra nota suelta, a un extraño contar de los días de la semana. No que en conjunto el libro no tenga un sentido entre todos sus textos (el tiempo, el lenguaje, la belleza, la desolación), pero esa semana que va del lundi (en francés el original) como "locura" al dimanche como lo eterno, resulta especialmente atractiva para el lector obsesionado por del lenguaje. Y la semana es acerca de Artaud. El lunes Artaud esta loco. Se queda cerca de la locura. Viéndola respirary no respirar. La semana continúa con versos que cruzan imágenes de la vida y obra de Artaud con las ideas sobre la poesía y la soledad de Carson. Al pie de los días de este semanal, frases que rechazan o ansían ejemplificar lo dicho en el texto de cada día de la semana. El viernes es un corto ensayo: La aventura de Artaud resiste la exégesis clínica o crítica, es una protesta en contra de la mismisima ejemplificación. Al pie de ese vendredi: What holes, and made of what?. El jueves es para Artaud y México: En México es útil tener la obsesión de contar./ Porque él se pierde en la membrana/ que brilla como un sol pulverizado/ y solo al 'sumar sombras' puede él encontrar su camino de regreso/ a extraños centros. Artaud en México, a ojos de Carson, es un antropólogo del único rito de la tribu que es él mismo: Like many a white man here he wants to believe in/ God's birth. / Stare at it for hours.

Trouxa Frouxa roza otros tópicos, no es de la tela clásica sino de la simple cotidianidad que Arêas saca la misma materia prima que Carson. Porque la lección de Zambrano se aprende ya sea de leer los clásicos con cuidado o de reparar (un decir) en la sonrisa de una hija pequeña al sorprendernos a la vera de la cama. Donizete Galvão lo dijo, no yo. Dijo que Zambrano alumia as palavras: Aprende-se com ela a colher do silêncio/ da solidão que vem desde a infância / palavras que precisam ser escritas. Así Arêas cuando nos narra una estampa, "Amor", que es el encuentro de un amor esporádico y lúmpen. El laconismo del acto es también una res poética, porque el laconismo es lo que las palabras a menudo quieren (a voz. contida fala mais que gritaria, Galvão): Cuenta Arêas:

\footnotetext{
Sabe que você é mesmo maluca, ele disse. E você vai ficar de pau mole com tanto crack, ela retrucou. A cama era um colchão estreito no assoalho. Ele conferiu como sempre a linha curva do pescoço, a escala das costelas, uma a uma, até mergulhar no talho fundo da cintura. Ela disse, vou cortar os peitos, cresceram muito, é da idade. Mas é bonito, ele disse, aconchegando na palma um seio quente como um ovo recém-posto. Ela adormeceu vendo estrelas negras sobre cactos batidos de areia. O vaz̧io da ausência de luæ.
}

En otra imagen de "Amor", la mujer es sometida por el deseo de un hombre que hace lo que hacen los hombres (montar, estrujar, eyacular y dormir); el final es punzante, para el hombre y la mujer: Ela tem nojo do beijo encharcado e do suor do corpo.

Los relatos de Arêas son así cortos, aparentemente simples, pero hijos de una mirada lacerante que tanto se burla de sí misma como se otorga pequeños regalos. Ya en 1976 no creía en la certeza: Situações certas são o vaz̧io admitido entre duas situações erradas. Y en el 2000 canta victoria: pela primeira vez na vida tenho a noção do que seja ser feliz sem qualquer excitação. Esta misma triste tranquilidad muestra Carson en sus lecturas y escrituras. En el "Apéndice al tiempo ordinario", una corta nota da noticia de que la madre de Carson muere mientras escribía Men in the Off Hour. Carson relata la lectura de los diarios de Virginia Woolf en busca de consuelo por la perdida. Es al tiempo, dice Carson, que 
debemos este placer de reiniciar la lectura y la escritura en el medio de la tristeza que es vivir y perder. Las intenciones de ver a, o hablar con, el ser querido no mueren, por ello duelen más que la muerte misma de la persona amada que estuvo siempre tras un viaje, corto a largo, una línea telefónica. La soledad le fue menos para Carson en esas horas por leer en los diarios de Woolf el registro inmediato anterior a la muerte: Es extraño que el sol deba estar brillando, y los pájaros cantando. Porque aqui. . .

Arêas, por su parte, piensa en un hijo que rememora al padre e chora. El padre que teria hoje cento e trinta e três anos. Un muerto. Como está frio este vulcão. Y la imagen se pierde en el degradarse del cadáver de ese amor, una existencia vital lutando com a farofa. Os dentes mergulhados no copo, a borda de coral lambida pela água turva, o cheiro que embebeda, os pedacinhos de ossos.

Arêas tiene el ojo urbano que la lengua portuguesa ha sabido cultivar como pocas. Y hace de los avatares de las calles poemas donde se siente el hedor, los ruidos y la soledad que la calle otorga. Los historiadores de ciudades abusan de Berlín, en busca de ser Benjamín, pero ni Walter tenía la nariz y el oído para hallar el humor y el hedor que en portugués se encuentra en Fernando Pessoa, Joãn do Rio o Cesário Verde: Nas nossas ruas, ao anoitecer,/ Há tal soturnidade, há tal melancolia,/ Que as sombras, o bulício, o Tejo, a maresial Despertam-me um desejo absurdo de sofrer. Y es con saudade de mí, como dice Sá Carneiro, de mis propias caminatas urbanas y mis capturas de momentos, que leo con envidia cuando Arêas atrapa al portero que sufre la orinada de un trasnochado, y el momento sublime en que el incontinente le grita: - Mijo de pai, perfume de rosas. Respeite e pau que te gerou Fingi que não era comigo. O cuando describe el encuentro de uma carola bem velha que andava dez.para as duas, cada pé prum lado como se estivesse dançando balé, flaca y con la lana que la cubre agujereada, orificio por donde se introduce una cucaracha, y el zoom del autor no para ahí, va más adentro: Acho que até hoje aquela barata mora lá com sua ninhada, chego a sonhar com isso. Pelo tempo, os filhotes devem estar todos bem crescidinhos e produzindo outras baratas em série como é muito natural. Además de un ojo en la ciudad y sus personales, Arêas ve a los niños. Aquí y allá aparece infancia, tratada no como fuente de inocencia sino de extraña y vital sabiduría. Ante ella, se achata la desesperanza de Arêas. De ella no se burla Arêas. Calla y aprende: una niña de dos años ante la luna: Olha lá no céu, olha lá a unha que eu acabei de roer.

De un hallazgo que viró acompañamiento pertinaz, de eso he hablado: del descubrimiento de un libro y sus ecos. Y han salido a cuento las voces de muchas mujeres. No era mi intención, pero un hallazgo llevó a otro y si salió femenino el acento no fue astucia mía sino de la naturaleza del hallazgo. Disertar sobre mujeres y literatura es de críticos y críticas. Mas cuando la conciencia del hallador de libros fluye de súbito sobre una creciente de clarividencia femenina, al venturoso no le toca disertar sino oir: dejarse llevar. Eso hice.

\section{Notas}

1 ZAID, Gabriel. Los demasiados libros. Barcelona: Anagrama, 1996.

2 CARSON, Anne. Men in the off Hour. New York: Alfred A. Knopf, 2000.

3 ARÊEAS, Vilma. Trouxa frouxa. São Paulo: Companhia das Letras, 2000. 
4 CARSON, Anne. Autobiography in Red. New York: Alfred A. Knopf, 1998.

5 ARÊAS, Vilma. Partidas. Rio de Janeiro: Livraria Francisco Alves Editora, 1976 e A Terceira perna. São Paulo: Editora Brasiliense, 1992.

6 ARGULLOL, Rafael. El caçador d’instants. Barcelona: Destino, 1996.

7 VITALE, Ida. Léxico de afinidades. Madrid: Ediciones El Cobre, 2006.

8 ZAMBRANO, María. Filosofía y poesía. México: Fondo de Cultura Económica,1993.

9 CARSON, Anne. The Beauty of the Husband: a Fictional Essay in 29 Tangos. New York: Alfred A. Knopf, 2001. 